University of Wollongong

Research Online

Faculty of Social Sciences - Papers (Archive) Faculty of Arts, Social Sciences \& Humanities

2014

Instructional strategies to promote incremental beliefs in youth sport

Stewart A. Vella

University of Wollongong, stvella@uow.edu.au

Dylan P. Cliff

University of Wollongong, dylanc@uow.edu.au

Anthony D. Okely

University of Wollongong, tokely@uow.edu.au

Dana L. Weintraub

Stanford University

Thomas N. Robinson

Stanford University, tom.robinson@stanford.edu

Follow this and additional works at: https://ro.uow.edu.au/sspapers

Part of the Education Commons, and the Social and Behavioral Sciences Commons

Research Online is the open access institutional repository for the University of Wollongong. For further information contact the UOW Library: research-pubs@uow.edu.au 


\title{
Instructional strategies to promote incremental beliefs in youth sport
}

\author{
Abstract \\ Implicit beliefs about the nature of human abilities have significant motivational, behavioral, and affective \\ consequences. The purpose of this article was to review the application of implicit beliefs to the youth \\ sport context and to provide theoretically derived and evidence-based instructional strategies to promote \\ adaptive implicit beliefs about human abilities within this context. A narrative overview of theory and a \\ review of research pertaining to implicit beliefs in education, sport, and physical activity are undertaken. \\ Theoretically derived and evidence-based instructional strategies are outlined, and specific coaching \\ behaviors are suggested. Six instructional strategies to promote adaptive implicit beliefs in these \\ contexts are suggested: focusing on effort and persistence, facilitating challenge, promoting the value of \\ failure, defining success as effort, the promotion of learning, and providing high expectations. It is \\ concluded that instructional strategies may be used to facilitate positive motivational, behavioral, and \\ affective outcomes for young people within a sport context. \\ Keywords \\ beliefs, strategies, incremental, instructional, promote, sport, youth \\ Disciplines \\ Education | Social and Behavioral Sciences

\section{Publication Details} \\ Vella, S. A., Cliff, D. P., Okely, A. D., Weintraub, D. L. \& Robinson, T. N. (2014). Instructional strategies to \\ promote incremental beliefs in youth sport. Quest, 66 (4), 357-370.
}


2

3

4

5

6

Instructional Strategies to Promote Incremental Beliefs in Youth Sport

7

8

Suggested Running Head: PROMOTING INCREMENTAL BELIEFS

9

10

Date of submission: 27/02/2014

11

12 
Abstract

15 Implicit beliefs about the nature of human abilities have significant motivational, behavioral, 16 and affective consequences. The objective of this paper was to review the application of 17 implicit beliefs to the youth sport context, and to provide theoretically-derived and evidence18 based instructional strategies to promote adaptive implicit beliefs about human abilities 19 within this context. A narrative overview of theory and review of research pertaining to implicit beliefs in education, sport and physical activity are undertaken. Theoretically-derived

21 and evidence-based instructional strategies are outlined and specific coaching behaviors are

22 suggested. Six instructional strategies to promote adaptive implicit beliefs in these contexts

23 are suggested, and include: A focus on effort and persistence; facilitating challenge;

24 promoting the value of failure; defining success as effort; the promotion of learning; and

25 providing high expectations. It is concluded that instructional strategies may be used to

26 facilitate positive motivational, behavioral and affective outcomes for young people within a

27 sport context. 
Instructional Strategies to Promote Incremental Beliefs in Youth Sport

Fundamental implicit beliefs about the nature of human abilities as either a fixed or

malleable trait have significant short- and long-term implications for individuals’

motivational frameworks, including their beliefs, affect, attributions, and behaviors (Dweck, 1999, 2006; Dweck \& Leggett, 1988). This is true in child and adolescent sports contexts where research has shown that beliefs about the nature of athletic ability predict motivation, enjoyment, interest, persistence, goal orientation, self-efficacy, positive affect, motor development, and skill acquisition (Biddle, Wang, Chatzisarantis, \& Spray, 2003; Jourden, Bandura, \& Banfield, 1991; Kasimatis, Miller, \& Marcussen, 1996; Van-Yperen \& Duda, 1999). Given the significant psychosocial and health benefits associated with participation in organized sports in childhood and adolescence (Fraser-Thomas, Côté, \& Deakin, 2005), coupled with high rates of drop-out from youth sports among children and adolescents (Hedstrom \& Gould, 2004), implicit beliefs about ability are an important avenue of research within these contexts. The implications and applications of such research would be relevant to fields including sports psychology, coaching, physical education, and public health.

Implicit beliefs are acquired beliefs about the nature of human abilities (Gunderson et al., 2013). These beliefs exert a strong influence on human behavior because they provide an underlying framework for the interpretation and response to events within an achievement context (Dweck \& Leggett, 1988). There are two basic types of implicit beliefs: incremental beliefs, and entity beliefs. Those who hold an incremental belief operate under the assumption that ability is a malleable, fluid, and changeable quality that can be developed (herein referred to as incremental beliefs). In contrast, those who hold an entity belief operate under the assumption that ability is a fixed, concrete, and internal entity (herein referred to as entity beliefs). Research consistently shows that incremental beliefs are associated with more 
adaptive responses including higher rates of motivation, persistence, and effort, a greater preference for challenge, and an ability to generate strategies for improvement (Blackwell, Trzesniewski, \& Dweck, 2007; Dweck \& Leggett, 1988; Gunderson et al., 2013).

Furthermore, implicit beliefs are particularly powerful predictors of adaptive responses following failure or setback (Dweck \& Leggett, 1988). Those who hold incremental beliefs of athletic ability are concerned with mastering new skills. As such, failure is not seen as a setback, but is seen as an opportunity to learn. Failure also provides an indication that greater effort is required. Alternatively, those who hold entity beliefs of athletic ability feel the need to validate their ability through athletic successes. Challenges represent greater potential risks to their perceptions of competence, and response to failures are significantly more negative because failure is indicative of inadequacy (Dweck, 1999). Furthermore, it is important to note that implicit beliefs about ability exert a strong influence on behavior regardless of the true nature of ability as either fixed or malleable. Ability has been defined as an inherited and relatively stable trait that is not easily modifiable with practice (Schmidt \& Lee, 2011). On the other hand, skills are seen as modifiable with practice, but only within the limits of one's ability (Schmidt \& Lee, 2011). However, consistent with a large body of previous work pertaining to implicit beliefs, and consistent with a lay definition, we make no differentiation between ability and skill.

Given the significant repercussions that implicit beliefs have on participation in organized sports and physical activity, and their associated psychological benefits, it is important to understand how these beliefs develop. Individual differences in implicit beliefs of various human attributes begin to emerge in the preschool years (Giles \& Heyman, 2003; Smiley \& Dweck, 1994). However, it is likely that implicit beliefs have their genesis in social and environmental antecedents that are encountered even earlier than this (Gunderson et al., 2013). In the sports context, a primary social influence responsible for the development of 
incremental beliefs is the coach (Slater, Spray, \& Smith, 2012). However, it is currently unclear exactly how this process occurs. Experimental procedures successfully used to temporarily manipulate implicit beliefs regarding athletic ability demonstrate that it is possible to induce incremental beliefs through instruction (Spray, Wang, Biddle, Chatzisarantis, \& Warburton, 2006). This is consistent with a large body of literature demonstrating the primary social influence of the coach on the behaviors and cognitions of young people, especially within the sporting context (Côté, Bruner, Erickson, Strachan, \& Fraser-Thomas, 2010). However, an individual's underlying implicit beliefs do not necessarily translate into corresponding communication patterns. It has been shown that parents who hold incremental beliefs are more likely to communicate to their children in ways that facilitate entity beliefs than incremental ones (Gunderson et al., 2013). This may be because adults find it difficult to turn their own incremental beliefs into communication patterns that are consistent with that belief. Alternatively, it may be that the desire to increase children's self-esteem by focussing on their ability (and thus reinforcing entity beliefs) works against parents who wish to communicate more adaptive incremental beliefs. Therefore, the purpose of this paper is to briefly review critical findings on implicit beliefs, and to provide instructional strategies that can be used to promote incremental beliefs regarding athletic ability within youth sport contexts.

\section{Implicit Belief Research}

$$
\text { Diener and Dweck (1978) provided some early evidence for the mechanisms by }
$$

which incremental beliefs may lead to more adaptive outcomes by showing that children who focussed on mastery engaged in higher rates of solution-directed behaviors such as selfmonitoring in order to produce future successes following failure. In contrast, these experiments indicate that children who attribute failure to a lack of ability experienced disproportionate decrements to their perceived ability, resulting in a more negative view of 
the future. In order to explain these results, and to explain why some children adopt a mastery goal orientation and others adopt a performance goal orientation, Dweck hypothesized a higher level cognitive pattern constituted by implicit beliefs about the nature of human ability (Dweck, 1999). According to the resultant socio-cognitive theory of achievement motivation (Dweck \& Leggett, 1988), children who believe that ability is a malleable quality (incremental beliefs) are more likely to adopt a mastery goal orientation. On the other hand, children who believe that ability is a fixed trait (entity beliefs) are more likely to become focussed on performance. Research generated by this model has since confirmed that the adoption of incremental beliefs regarding one's intelligence predicts higher rates of academic achievement across childhood, adolescence, and beyond (Aronson, Fried, \& Good, 2002; Blackwell et al., 2007; Good, Aronson, \& Inzlicht, 2003). Consistent with this early work, a recent meta-analysis shows that incremental beliefs predict goal setting, goal operating, and goal monitoring, which in turn predict goal achievement. More specifically, the relationship between implicit beliefs and goal achievement is partially mediated by the adoption of learning goals, mastery-based strategies, and high expectations, as well as the avoidance of negative emotions and "helpless" responding (Burnette, O'Boyle, VanEpps, Pollack, \& Finkel, 2013). Longitudinal research indicates that the result of self-regulatory strategies that are derived from incremental beliefs is an upward trajectory in performance, while entity beliefs result in a flat trajectory over time (Blackwell et al., 2007). Interventions have shown that the adoption of incremental beliefs lead to increases in academic performance and classroom motivation (Aronson, Fried, \& Good, 2001; Aronson et al., 2002; Blackwell et al., 2007). Despite the plethora of research that has been generated within the academic setting, substantially less has been focussed on the sporting domain. Given the differences between the two contexts, it is worth examining the generalizability and applicability of implicit belief research within the sporting domain through a review of research. 


\section{Critical Research Findings on Implicit Beliefs within Sports}

Research has established the cross-sectional relationship between implicit beliefs of ability and achievement goals within sport and physical activity contexts (Biddle et al., 2003;

Cury, Da Fonseca, Rufo, \& Sarrazin, 2002; Lintunen, Valkonen, Leskinen, \& Biddle, 1999;

Ommundsen, 2001; Sarrazin et al., 1996). A review of this literature shows that implicit beliefs about ability are critical elements of all other major theories of motivation, including achievement goal theory, attribution theory, self-efficacy, and intrinsic motivation (Li \& Lee, 2004). Furthermore, research indicates that implicit beliefs about athletic ability are positively associated with enjoyment of physical activity (Biddle et al., 2003). When incremental beliefs about athletic ability are induced participants report more adaptive responses to difficult tasks including greater motivation, self-efficacy, interest, positive affect, and motor development than those who perform the tasks under entity beliefs (Jourden et al., 1991; Kasimatis et al., 1996). Athletes who hold incremental beliefs of athletic ability also show greater rates of skill improvement than their peers (Van-Yperen \& Duda, 1999). Lastly, qualitative research with high-performance athletes shows that implicit beliefs have their genesis in a variety of personal, social, and environmental antecedents such as selfreflection, observational-learning, coaching, parenting, and club structure (Slater et al., 2012).

\section{Components of Incremental Beliefs}

The six instructional strategies outlined below represent the major components derived from theory and research that we propose for principles of best practice for coaching youth sports. Each instructional strategy has been generated through an operationalization process involving extensive literature review, a modified Delphi process, and expert review. Additionally, each instructional strategy is drawn from a single, underlying, and implicit belief system with the aim of increasing incremental beliefs. As such, the instructional strategies are interdependent and include a degree of conceptual convergence. However, in 
the youth sport and physical activity context minimizing behaviors that promote entity beliefs is also important because entity beliefs have been associated with greater maladaptive outcomes such as amotivation (Biddle et al., 2003). Where the research is sufficiently strong to make such recommendations, coaching behaviors to be minimized are also suggested. A summary of these principles of best practice appears in Figure 1.

Focus on effort and persistence. Belief in incremental beliefs of athletic ability in its most basic form is the admission that mastery is under one's own control and is thus dependent on effort and persistence (Dweck,1999). Those who are oriented toward entity beliefs of athletic ability, however, see hard work and effort as indicators of low levels of ability. At its logical conclusion, this may be reflected in the belief that if one is endowed with natural talent then hard work is unnecessary, and if success is contingent upon effort then one must not be talented. Research indicates that children who hear praise for effort come to believe that the sources of their accomplishments are effort and deliberate practice, whereas children who hear praise for ability come to believe that the sources of their accomplishments are fixed traits (Zentall \& Morris, 2010). Instructional strategies may therefore be used to facilitate incremental beliefs of athletic ability by praising effort, persistence, and practice. This is held to be true even in childhood sports where deliberate play, as opposed to deliberate practice, is considered as best practice coaching (Côté, Lidor, \& Hackfort, 2012).

The promotion and facilitation of deliberate practice may be especially important following a setback, such as losing a match or subpar personal performance. When athletes high in entity beliefs encounter a setback they tend to give up because under this framework failure is indicative of low ability. This "helpless” response is typical of those who hold external control beliefs and may generate low levels of self-efficacy (Lirgg, Chase, George, \& Ferguson, 1996). A combination of the belief that ability is a stable entity with low 
perceived self-efficacy may lead athletes to hold very little hope that effort and hard work will lead to gains in mastery (Ommundsen, 2003).

There are many ways for a coach or educator to promote athletes' focus on effort and persistence. Former UCLA basketball coach John Wooden elevated such behaviours to cornerstones of his coaching philosophy. In his 'Pyramid of Success' Wooden advocated for Industriousness and Intentness, pointing out that success travels in the company of hard work, and encouraged his players to 'stay the course' when thwarted, and to persevere relentlessly (Wooden \& Jamison, 2004). Other strategies include, where contextually appropriate, young athletes who have worked the hardest to improve at practice earn a starting position. Additionally, the coach should respond to athlete mistakes by giving feedback centred on effort and hard work. For example, the coach may respond to a mistake by providing some technical or tactical correction, followed by a statement regarding the importance of persistent practice in mastering the skill in question. In this way, it is similar to the 'sandwich' approach advocated by Smoll and Smith (2009), with an added emphasis on effort and persistence. Research indicates that praise for effort and persistence (process praise), as opposed to praise for ability is associated with the development of incremental beliefs up to five years later (Gunderson, 2013). Further, this research also shows evidence of a doseresponse relationship, with more process praise associated with stronger incremental beliefs (Gunderson et al., 2013). Another strategy may be to provide the conditions necessary for deliberate practice, or to encourage multiple attempts at difficult tasks. The coach may do this by allocating large amounts of time to deliberate practice (for example, as opposed to deliberate play), and thus allowing athletes to make explicit attempts to improve their ability. Challenge. Those who hold entity beliefs are concerned with outcomes. This manifests itself as an inclination to reject opportunities for learning and improvement provided by difficult tasks (Dweck, 1999; Dweck \& Leggett, 1988). Tasks with a high risk of 
failure may be avoided because ability will be invalidated if failure occurs. This may be particularly so for athletes low in self-efficacy and high in entity beliefs (Ommundsen, 2003). Fry (2000) has shown that, if given the choice, approximately one third of school children aged 5 to 13 years preferred to play an easy game that did not provide challenge. These children are likely to be those at highest risk of displaying maladaptive motivational patterns as a result of entity beliefs (Fry, 2000). In contrast, young people who are high in incremental beliefs seek out the challenge inherent in difficult tasks because challenges provide essential feedback on skills and an opportunity to learn. Thus, the coach may facilitate incremental beliefs of athletic ability through the explicit promotion and facilitation of engagement in appropriately difficult tasks as the means to achievement within a supportive environment. Challenge is one of the most important motives for participation in youth sports (Gould, Feltz, \& Weiss, 1985). Researchers have suggested that gains in motivation are optimized when the level of challenge is perceived to be moderately difficult, but not unrealistic (Cox, 2007). Children and adolescents enjoy activities that extend their current skill set, and may become amotivated when required to complete skills over which they have already achieved mastery (Lepper, Master, \& Quin Yow, 2008). The coach should set new, challenging goals that provide an opportunity for the mastery of new skills within a mastery climate, and avoid repetition of skills over which children have already achieved mastery. Pat Summitt who won over 1,000 games as coach of the University of Tennessee Women’s Basketball team puts it like this: "Setting goals is incredibly important to success. But if you set a goal that seems impossible to achieve - if you go into a year saying your goal is to win the national championship - then you risk losing morale, self-discipline and chemistry if you falter early. Set a goal that stretches you, requires exceptional effort, but one that you can reach” (Yaeger, 2013). Furthermore, according to Morgan and Carpenter (2002) a coach may facilitate and promote engagement in challenge through their behavior and communications, 
through the practices that they set, or through the climate they create. For example, the coach may praise athletes who unsuccessfully attempt difficult tasks, or they may encourage risktaking during practice, set training drills that are of moderate difficulty, or facilitate a mastery climate where attempting difficult tasks in the pursuit of mastery is valued.

Value of failure. A firm belief in the value of failures and setbacks is a core component of incremental beliefs. Dweck (1999) has most poignantly shown this by demonstrating that the performance of children who hold incremental or entity beliefs is parallel until failure occurs. This is due to important adaptive differences in response to failure. Young people high in incremental beliefs see failure as a temporary setback that provides an opportunity for feedback on performance and ability, while young people high in entity beliefs see failure as an enduring indication of low levels of ability (Dweck, 1999). Thus, those high in incremental beliefs respond to failure with adaptive responses such as solution-focussed self-instruction, increased effort, and improved performance. Individuals high in entity beliefs respond to failure with maladaptive responses by attributing failure to low ability, and by exhibiting negative affect, decreased effort, and decreased motivation (Elliott \& Dweck, 1988). Therefore, facilitating a belief in the value of failure is a key strategy to promote incremental beliefs in athletic ability. Alex Ferguson, whose coaching tenure at Manchester United Football Club spanned three decades takes this view. He writes "Sometimes defeats are the best outcomes. To react to adversity is a quality...If you are lackadaisical about defeats you can be sure there will be more to come. Often we would drop two points in a game by the opposition equalising with the last kick of the ball and then go on a six or seven game winning run. It was not a coincidence” (Ferguson, 2013; p 30). As such, Ferguson encapsulates what it means to find value in failure and to use it to improve performance. 
To understand the value of failure, the skills of monitoring performance, reflecting,

255

256

257 and revising learning strategies are important skills for children and adolescents to learn (Larson, 2011). Ommundsen (2003) has found that physical education students who hold incremental beliefs are more likely to plan, monitor, and regulate their cognitions over different learning tasks than their entity belief peers. Pupils who believe that effort, hard work, and persistence lead to mastery also perceive themselves to be more in control of their own learning and are more likely to monitor their goals, adapt, and change their strategy, especially following setbacks (Skinner, 1995). As such, the coach should encourage reflection, and provide a strategy to improve following setbacks. Even a failure that is viewed positively may lead to the helpless response if there is no accompanying strategy for improvement. Strategies may be as simple as increased effort and persistence, or may include technical or tactical reflection. Research also shows that enthusiastic instructors who provide high interaction, supportive feedback, and clear goals that emphasize learning will increase the use of self-regulated learning strategies (Young, 2005). It is also important that the coach does not unreasonably deny mistakes or failures by providing external attributions when failure occurs or promote entity beliefs of athletic ability by providing stable internal attributions to failure. Failures should be accurately attributed to internal, temporary causes where possible, and should be paired with a strategy to address them, preferably focussing on effort. Research has shown that athletes taught to make facilitative attributions to failure are more inclined towards mastery and show greater improvement in performance (Miserandino, 1998).

Perception of success. Children's perceptions of success are critical predictors of motivational and behavioral responses in achievement settings (Lepper et al., 2008).Importantly, those who hold incremental beliefs are more inclined to increase their effort after a failure because they don’t perceive “failure” to be a setback, and because they 
believe that success is derived from effort (Dweck, 1999). In contrast, those high in entity beliefs hold that one must necessarily be endowed with natural talent in order to be successful. Such beliefs lead to maladaptive responses to perceived failures including motivational deficits, withdrawal, and low self-efficacy (Sarrazin et al., 1996). According to Wooden, one may be successful if he or she gives their best effort, even in the absence of success or mastery. This is important because the explicit promotion of effort and persistence has already been advocated. A coach should not promote effort and persistence as the contingencies of success without also adjusting the definition of success. For example, even in the company of extremely hard work, one is not guaranteed to win, nor to achieve mastery if the conditions surrounding such hard work are not conducive to the development of mastery. For example, poorly designed training sessions such as a lack of sufficiently difficult tasks may hinder the development of mastery. In these cases, the athlete must still be able to control his or her own success. If a coach promotes effort and persistence without similarly adjusting their definition of success, youth may be persistent in working hard and yet see little improvement in performance, and thus adopt entity beliefs of athletic ability. As outlined by Lepper and colleagues (2008), young people enjoy activities at which they are able to succeed. However, the motivational powers of feelings of competence are delicate, particularly when success is not attained. When young people feel that the outcome of success is not under one's control they experience the helpless response (Seligman, 1975). Lepper and colleagues (2008) argue, therefore, that feelings of control depend critically on attributions for success that emphasize factors under one’s own control, such as effort. Further, externally referenced control beliefs may lead to the assumption that effort and hard work are futile (Ommundsen, 2003).

Coach Wooden was able to make success attainable for all by explicitly defining success as giving your best effort, and by maintaining consistency between his behavior and 
this definition (Wooden \& Jamison, 2004). A coach may also facilitate this belief by downplaying the importance of winning, and emphasising the importance of the "process" over "outcome”. For example, a coach who is consistent with this definition will indicate his/her satisfaction with an effortful performance despite losing the game by a big margin.

Promote learning. The promotion of learning goals and a mastery climate can be effective instructional strategies to induce incremental beliefs about performance. According to Dweck’s Social Cognitive Model of Achievement Motivation incremental beliefs give rise to learning goal orientations (Dweck \& Leggett, 1988). This model has been validated within an adolescent physical activity context (Biddle et al., 2003). However, the adoption of a learning goal orientation within sports also predicts the adoption of incremental beliefs, regardless of the extent of adoption of entity beliefs (Sarrazin et al., 1996). Therefore, the promotion of a learning goal orientation can work to facilitate incremental beliefs, even among those who are high in entity beliefs. Furthermore, implicit beliefs can affect motivation to persist at a task, even if the task is non-competitive or has no clear performance criterion, and therefore would not be hindered by the promotion of learning goals (Kasimatis et al., 1996).

The benefits of learning goal orientations in youth sport and physical activity contexts are well established. Benefits include increased perceptions of competence, enjoyment, persistence, motivation, and effort, as well as decreased anxiety and immoral behavior (Duda, 2005; Newton \& Duda, 1999). Physical educators are able to manipulate the motivational climate towards mastery to induce students’ preference for challenging tasks, satisfaction, positive attitudes, and increases in motor skill development (Morgan \& Carpenter, 2002; Robinson, 2011). Additionally, perceptions of a mastery-oriented motivational climate are associated with the belief that motivation or effort is the cause of 
success. In contrast, perceptions of a performance climate are negatively associated with physical education students' preference for challenging tasks (Treasure et al., 2001). Ames (1992) has provided a comprehensive outline of instructional strategies and structures that support a focus on learning. Task-based instructional strategies include: Design tasks for reasonable challenge; help students establish short-term, self-referenced goals; support the use of effective learning strategies; and, design tasks for novelty, variety, and interest. Authority-based instructional strategies include: Allow students to participate in decision making; provide choices to students where decisions are based on effort; allow students to develop independence; and, support the development of self-management and monitoring skills. Evaluation-based instructional strategies include: Focus on individual improvement, and mastery; make evaluation private and not public; praise students' effort; provide opportunities for improvement; and, encourage a view of mistakes as part of learning. Given the close theoretical ties (Dweck \& Leggett, 1988) between implicit beliefs and goal orientations, it is unsurprising that there is some overlap between the strategies provided by Ames (1992) and those suggested here.

High expectations. The explicit provision of appropriately high expectations that are above current achievement levels send strong messages to youth that abilities are incremental because they involve the need for improvement. Furthermore, children and adolescents can be transformed through the provision of such expectations (Dweck, 2006). Indeed, high expectations are an integral mechanism by which implicit beliefs work to increase goal attainment (Burnette et al., 2013). It is hypothesized that providing high performance expectations serve to increase self-efficacy (Avolio \& Bass, 2002). More specifically, Slater and colleagues (2012) suggest that, consistent with Bandura’s Self Efficacy Theory (Bandura, 1997), providing high expectations may allow the athlete to experience positive performance accomplishments and vicarious experiences which serve to increase self-efficacy and 
353 demonstrate that ability is acquirable. Furthermore, high performance expectations are a

354 central component of Transformational Leadership theory as it has been applied to sports

355 coaching (Callow, Smith, Hardy, Arthur, \& Hardy, 2009). Also referred to as inspirational

356 motivation, high performance expectations can be used to demonstrate to athletes that ability

357 is malleable and to motivate them to increase their ability. However, high performance

358 expectations should be delivered from within an encouraging and supportive environment

359 that promotes independence and self-management. This is because high performance

360 expectations, when delivered in a maladaptive context, may have negative consequences

361 (Hardy et al., 2010). Thus, the successful application of high performance expectations,

362 especially within youth sport and physical activity contexts, is contingent upon contextual

363 factors including support, encouragement, and self-management strategies.

364 One way to provide high performance expectations is to set appropriate SMART

365 (specific; measurable; action-oriented; realistic; timely) goals (Cox, 2007). In particular, self-

366 determined performance and process goals (as opposed to outcome goals) can be an effective

367 strategy to promote incremental beliefs by confirming to athletes that ability is able to be

368 acquired, while also promoting learning, effort, and persistence, increasing motivation,

369 enabling learning strategies, and providing a means to monitor effort and performance.

370 Alternatively, the coach may promote incremental beliefs in athletic ability by selling a vision

371 of improvement or performance that is above the current level and by emphasizing the

372 potential of each athlete (Avolio \& Bass, 2002). Any process whereby young people can

373 envision a future self with a higher level of ability inherently communicates to that athlete

374 that ability is an incremental and acquirable asset.

Discussion

Beliefs about the nature of athletic ability predict motivation, enjoyment, interest,

377 persistence, goal orientation, self-efficacy, positive affect, motor development and skill 
378

379

380

381

382

383

384

385

386

387

388

389

390

391

392

393

394

395

396

397

398

399

400

401

402

acquisition in youth sport and physical activity contexts (Biddle et al., 2003; Jourden et al., 1991; Kasimatis et al., 1996; Van-Yperen \& Duda, 1999). This paper has proposed a theoretically-derived, evidence-based, and conceptually-related set of instructional strategies that may be used to promote incremental beliefs of athletic ability in these contexts and thereby facilitate adaptive outcomes for young people. Given the prominence of implicit belief research in the developmental, educational, and motivational literature the omission of theoretically-informed instructional strategies represents a substantial gap in knowledge. The addition of instructional strategies to the literature can help to generate new research questions and may have important implications and applications to sport pedagogy. While the instructional strategies that have been articulated above represent a novel application of theory to the youth sports context, it is notable that there is some overlap between these strategies and those presented within other approaches to coaching. Most notably, the Mastery Approach to Coaching (Smoll \& Smith, 2009) has as its central concept the promotion of learning. Related concepts also include an emphasis on the informational content of praise, and the definition of success by self-referenced means. However, given the close theoretical links between implicit beliefs and goal orientations (Dweck \& Leggett, 1988) this is perhaps unsurprising. Similarly, the transformational leadership approach to coaching in youth sports (Vella, Oades, \& Crowe, 2012) and the autonomy-supportive coaching approach (Mageau \& Vallerand, 2003) both share common instructional strategies with those presented here. These include the promotion of challenge and provision of contextually-appropriate high performance expectations. The extent to which these four approaches are distinct, as well as any potential common mechanisms by which each approach works to increase motivation are still unknown.

Although we have adopted a lay definition of ability and have made no distinction between ability and skill, the two have been considered as distinct constructs (Schmidt \& 
Lee, 2011). Our approach has been consistent with over two decades of research in implicit beliefs (Dweck \& Leggett, 1988), however, a more nuanced approach to terminology and measurement of implicit beliefs is required in the future. For example, it is unclear whether children can distinguish between the constructs of skill and ability, and if so, are implicit beliefs about ability or skill more predictive of motivation? These are important theoretical and applied issues that warrant further investigation.

Implementation of the six instructional strategies outlined above would require that youth sport coaches relinquish an emphasis on winning. Given the importance that is typically placed upon winning by athletes, parents, and administrators, this may be a difficult task for coaches. We have outlined empirical evidence which documents that the instructional strategies lead to adaptive behaviours such as effort, persistence, and practice, which are in turn important predictors of performance. However, coaches may need additional support to implement these strategies. Given that theoretically-based approaches to coach education have been poorly applied in the empirical literature (Langan, Blake, \& Lonsdale, 2013), it is currently unclear what the most effective way to support coaches in implementing such changes may be.

The first task for future research is to validate the instructional strategies as effective in increasing incremental beliefs within sports settings. Development of sensitive instrumentation to collect reliable data is a first step in accomplishing this task. A tool to systematically observe instructional strategies may be especially important for research in settings where children are too young to complete self-report measures. Questions of particular importance are: 'how influential is the coach in the genesis of implicit beliefs about sporting ability, especially in comparison with other social influences such as parents?'; ‘do coaches of younger athletes have a greater influence?'; and, 'how long lasting is the impact of the coach?'. An avenue for future research may be the use of the framework provided by 
428 these instructional strategies to aid coach development. Moulding coaching behaviors

429 according to this framework is a priority, examining its impact on theory-driven outcomes for

430 young people such as motivation, persistence (including dropout), and goal orientations

431 within sport and physical activity. Also of importance is research that can examine potential

432 susceptible periods and contexts for the development of implicit beliefs. For example, is the

433 impact of a young athlete's first coach greater than that of subsequent coaches? Questions

434 such as this may become especially important in the near future given the broad array of

435 psychosocial and health benefits that are a result of participation in organized sports during

436 childhood (Fraser-Thomas et al., 2005).

437 
439

440

441

442

443

444

445

446

447

448

449

450

451

452

453

454

455

456

457

458

459

460

Ames, C. (1992). Classrooms: Goals, structures, and student motivation. Journal of Educational Psychology, 84, 261-271.

Aronson, J., Fried, C. B., \& Good, C. (2001). Reducing the effects of stereotype threat on African American college students by shaping implicit theories of intelligence. Journal of Intervention Social Psychology, 38, 1-13.

Aronson, J., Fried, C. B., \& Good, C. (2002). Reducing stereotype threat and boosting academic achievement of African-American students: The role of conceptions of intelligence. Journal of Experimental Social Psychology, 38, 113-125.

Avolio, B. J., \& Bass, B. M. (2002). Developing potential across a full range of leadership: Cases on transactional and transformational leadership. Mahwah, NJ: Lawrence Erlbaum Associates.

Bandura, A. (1997). Self-efficacy: The exercise of control. New York: W.H. Freeman and Company.

Biddle, S. J. H., Wang, C. K. J., Chatzisarantis, N. L. D., \& Spray, C. M. (2003). Motivation for physical activity in young people: entity and incremental beliefs about athletic ability. Journal of Sports Sciences, 21, 973-989.

Blackwell, L. S., Trzesniewski, K. H., \& Dweck, C. S. (2007). Implicit theories of intelligence predict achievement across adolescent transition: A longitudinal study and an intervention. Child Development, 78, 246-263.

Burnette, J. L., O’Boyle, E. H., VanEpps, E.M., \& Finkel, E. J. (2013). Mind-sets matter: A meta-analytic review of implicit theories and self-regulation. Psychological Bulletin, 139, 655-701. 
461 Callow, N., Smith, M. J., Hardy, L., Arthur, C. A., \& Hardy, J. (2009). Measurement of transformational leadership and its relationship with team cohesion and performance level. Journal of Applied Sport Psychology, 21, 395-412.

Côté, J., Bruner, M., Erickson, K., Strachan, L., \& Fraser-Thomas, J. (2010). Athlete development and coaching. In J. Lyle \& C. Cushion (Eds.), Sport coaching: Professionalism and practice. Oxford, UK: Elsevier.

Côté, J., Lidor, R., \& Hackfort, D. (2012). ICCP position stand: To sample or to specialize? Seven postulates about youth sport activities that lead to continued participation and elite performance. International Journal of Sport and Exercise Psychology, 7, 7-17.

Cox, R. F. (2007). Sport psychology: Concepts and applications. Boston: McGraw-Hill.

Cury, F., Da Fonseca, D., Rufo, M., \& Sarrazin, P. (2002). Perceptions of competence, implicit theory of ability, perception of motivational climate, and achievement goals: A test of trichotomous conceptualization of endorsement of achievement motivational in the physical education setting. Perceptual and Motor Skills, 95, 233-244.

Diener, C. I., \& Dweck, C. S. (1978). An analysis of learned helplessness: Continuous changes in performance, strategy, and achievement cognitions following failure. Journal of Personality and Social Psychology, 36, 451-462.

Duda, J. L. (2005). Motivation in sport: The relevance of competence and achievement goals. In A. J. Elliot \& C. S. Dweck (Eds.), Handbook of competence and motivation (pp. 318-335). New York: Guildford Publications.

Dweck, C. S. (1999). Self-theories: Their role in motivation, personality, and development. Philadelphia: Psychology Press.

Dweck, C. S. (2006). Mindset: The new psychology of success. New York: Random House.

Dweck, C. S., \& Leggett, E. L. (1988). A social-cognitive approach to motivation and personality. Psychological Review, 95, 256-273. 
Elliott, E. S., \& Dweck, C. S. (1988). Goals: An approach to motivation and achievement. Journal of Personality and Social Psychology, 54, 5-12.

Ferguson, A. (2013). My autobiography. London: Hodder \& Stoughton Ltd.

Fraser-Thomas, J. L., Côté, J., \& Deakin, J. (2005). Youth sport programs: An avenue to foster positive youth development. Physical Education and Sport Pedagogy, 10, 1940.

Fry, M. D. (2000). A developmental examination of children's understanding of task difficulty in the physical domain. Journal of Applied Sport Psychology, 12, 180-202.

Giles, J. W., \& Heyman, G. D. (2003). Preschoolers' beliefs about the stability of antisocial behavior: Implications for navigating social challenges. Social Development, 12, 182197.

Good, C., Aronson, J., \& Inzlicht, M. (2003). Improving adolescents' standardised test performance: An intervention to reduce the effects of stereotype threat. Journal of Applied Developmental Psychology, 24, 645-662.

Gould, D., Feltz, D., \& Weiss, M. (1985). Motives for participating in competitive youth swimming. International Journal of Sport Psychology, 16, 126-140.

Gunderson, E. A., Gripshover, S. J., Romero, C., Dweck, C. S., Goldin-Meadow, S., \& Levine, S. C. (2013). Parent praise to 1- to 3-year-olds predicts chidlren's motivational frameworks 5 years later. Child Development, 84, 1526-1541.

Hardy, L., Arthur, C. A., Jones, G., Shariff, A., Munnoch, K., Isaacs, I., \& Allsopp, A. J. (2010). The relationship between transformational leadership behaviors, psychological, and training outcomes in elite military recruits. The Leadership Quarterly, 21, 20-32.

Hedstrom, R., \& Gould, D. (2004). Research in youth sports: Critical issues status. Kansas City, Mo. 
Jourden, F., Bandura, A., \& Banfield, J. T. (1991). The impact of conceptions of ability on self-regulatory factors and motor skill acquisition. Journal of Sport \& Exercise Psychology, 13, 213-226.

Kasimatis, M., Miller, M., \& Marcussen, L. (1996). The effects of implicit theories on exercise motivation. Journal of Research in Personality, 30, 510-516.

Langan, E., Blake, C., \& Lonsdale, C. (2013). Systematic review of the effectiveness of interpersonal coach education interventions on athlete outcomes. Psychology of Sport and Exercise, 14, 37-49.

Larson, R. W. (2011). Positive development in a disorderly world. Journal of Research on Adolescence, 21, 317-334.

Lepper, M., Master, A., \& Quin Yow, W. (2008). Intrinsic motivation in education. In S. Karabenick \& T. C. Urdan (Eds.), Advances in motivation and achievement (pp. 521555). Bingley, UK: Emerald Group Publishing.

Li, W., \& Lee, A. (2004). A review of conceptions of ability and related motivational constructs in achievement motivation. Quest, 56, 439-461.

Lintunen, T., Valkonen, A., Leskinen, E., \& Biddle, S. J. H. (1999). Predicting physical activity intentions using a goal perspectives approach: a study of Finnish youth. Scandinavian Journal of Medicine \& Science in Sports, 9, 344-352.

Lirgg, C. D., Chase, M. A., George, T. R., \& Ferguson, R. H. (1996). Impact of conception of ability and sex-type of task on male and female self-efficacy. Journal of Sport \& Exercise Psychology, 18, 426-434.

Mageau, G. A., \& Vallerand, R. J. (2003). The coach-athlete relationship: A motivational model. Journal of Sports Sciences, 21, 883-904. 
Mangels, J. A., Butterfield, B., Lamb, J., Good, C., \& Dweck, C. S. (2006). Why do beliefs about intelligence influence learning success? A social cognitive neuroscience model. Social Cognitive and Affective Neuroscience, 1, 75-86.

Miserandino, M. (1998). Attributional retraining as a method of improving athletic performance. Journal of Sport Behavior, 21, online.

Morgan, K., \& Carpenter, P. (2002). Effects of manipulating the motivational climate in physical education lessons. European Physical Education Review, 8, 207-229.

Newton, M. L., \& Duda, J. L. (1999). The interaction of motivational climate, dispositional goal orientation and perceived ability in predicting indices of motivation. International Journal of Sport Psychology, 30, 63-82.

Ommundsen, Y. (2001). Students' implicit theories of ability in physical education classes: The influence of motivational aspects of the learning environment. Learning Environments Research, 4, 139-158.

Ommundsen, Y. (2003). Implicit theories of ability and self-regulation strategies in physical education classes. Educational Psychology: An International Journal of Experimental Educational Psychology, 23, 141-157.

Robinson, L. E. (2011). Effect of a mastery climate motor program on object control skills and perceived physical competence in preschoolers. Research Quarterly for Exercise and Sport, 82, 355-359.

Sarrazin, P., Biddle, S., Famose, J. P., Cury, F., Fox, K., \& Durand, M. (1996). Goal orientations and conceptions of the nature of sport ability in children: A social cognitive approach. British Journal of Social Psychology, 35, 399-414.

Schmidt, R.A., \& Lee, T.D. (2011). Motor control and learning: A behavioral emphasis (5 ${ }^{\text {th }}$ ed.). Champaign, IL: Human Kinetics.

Seligman, M. (1975). Helplessness. San Francisco: Freeman. 
559 Skinner, E. A. (1995). Perceived control, motivation and coping. Thousand Oaks: Sage.

560 Slater, M. J., Spray, C. M., \& Smith, B. M. (2012). "You're only as good as your weakest

561 link": Implicit theories of golf ability. Psychology of Sport and Exercise, 13, 280-290.

562 Smiley, P. A., \& Dweck, C. S. (1994). Individual differences in achievement goals among 563 young children. Child Development, 65, 1723-1743.

564 Smoll, F. L., \& Smith, R. E. (2009). Mastery approach to coaching: A leadership guide for $565 \quad$ youth sports. Washington: Authors.

566 Spray, C. M., Wang, C., Biddle, S. J., Chatzisarantis, N. L., \& Warburton, V. E. (2006). An 567 experimental test of self-theories of ability in youth sport. Psychology of Sport and Exercise, 7, 255-267.

Treasure, D. C., Duda, J. L., Hall, H. K., Roberts, G. C., Ames, C., \& Maehr, M. L. (2001). Clarifying misconceptions and misrepresentations in achievement goal research in sport: a response to Harwood, Hardy, and Swain. Journal of Sport \& Exercise Psychology, 23, 317-329.

Van-Yperen, N. W., \& Duda, J. L. (1999). Goal orientations, beliefs about success, and performance improvement among young elite Dutch soccer players. Scandinavian Journal of Medicine \& Science in Sports, 9, 358-364.

Vella, S. A., Oades, L. G., \& Crowe, T. P. (2012). Validation of the Differentiated Transformational Leadership Inventory as a measure of coach leadership in youth soccer. The Sport Psychologist, 26, 203-224.

579 Wooden, J. R., \& Jamison, S. (2004). My personal best: Life lessons from an All-American journey. New York, NY: McGraw-Hill Publishers. 
583 Young, M. R. (2005). The motivational effects of the classroom environment in facilitating 584 self-regulated learning. Journal of Marketing Education, 27, 25-40.

585 Zentall, S. R., \& Morris, B. J. (2010). "Good job, you're so smart": The effects of 586 inconsistency of praise type on young children's motivation. Journal of Experimental Child Psychology, 107, 155-163. 